\title{
Assessing the Profitability of Avocado Production in South Florida in the Presence of Laurel Wilt
}

\author{
Mauricio Mosquera1, Edward A. Evanss, ${ }^{1,2}$, Randy Ploetz ${ }^{2,3}$ \\ ${ }^{1}$ Food \& Resource Economics Department, Institute of Food \& Agricultural Sciences (IFAS), University of Florida, \\ Gainesville, FL, USA \\ ${ }^{2}$ Tropical Research \& Education Center (TREC), Institute of Food \& Agricultural Sciences (IFAS), Gainesville, FL, USA \\ ${ }^{3}$ Department of Plant Pathology, Tropical Research \& Education Center (TREC), Institute of Food \& Agricultural \\ Sciences (IFAS), Gainesville, FL, USA \\ Email: eaevans@ufl.edu
}

Received 22 March 2015; accepted 26 April 2015; published 29 April 2015

Copyright (C) 2015 by authors and Scientific Research Publishing Inc.

This work is licensed under the Creative Commons Attribution International License (CC BY).

http://creativecommons.org/licenses/by/4.0/

(c) (7) Open Access

\begin{abstract}
Laurel wilt (LW) is a lethal disease of trees in the Lauraceae plant family, including the economic significant commercial crop avocado, Persea americana. To date, an estimated one-half billion native trees have been destroyed by the disease in the southeastern United States, including the loss of significant and diverse taxa in the Everglades. In the US state of Florida, laurel wilt has spread rapidly throughout the South Florida commercial avocado production area. Since its arrival in 2011, LW has been responsible for the death of about 7000 trees or $1 \%$ of the production area. Given the destructive nature of this disease, there are major concerns over the future of the Florida avocado industry. Cost-effective management of LW remains an elusive goal, and current recommendations rely heavily on the early detection and destruction of affected trees (sanitation) in an effort to slow the spread of the disease. An empirical economic model is used to determine when all trees in an orchard affected by LW would need to be destroyed due to negative net returns.
\end{abstract}

\section{Keywords}

Avocado Production, Laurel Wilt, Profitability

\section{Introduction}

Laurel wilt (LW) has emerged as a lethal threat to plants in the Lauraceae plant family in the southeastern Unit-

How to cite this paper: Mosquera, M., Evans, E.A. and Ploetz, R. (2015) Assessing the Profitability of Avocado Production in South Florida in the Presence of Laurel Wilt. Theoretical Economics Letters, 5, 343-356. 
ed States (US Southeast), including important native trees and the commercial avocado crop, Persea americana [1] [2]. LW is caused by the fungus Raffaelea lauricola, which has an invasive ambrosia beetle vector, Xyleborus glabratus. Since 2002, an estimated one-half billion native trees have been destroyed by LW in the US Southeast. Significant environmental, ecological, and economic impacts have been documented throughout this region, as well as the loss of culturally significant and diverse taxa in the Everglades. Since its appearance in Florida commercial avocado production area in 2011, more than 7000 trees, representing approximately $1 \%$ of production area, have had to be removed. Commercial production has ceased in severely impacted orchards in Florida, and valuable avocado production in unaffected orchards and in other states (especially California) and the Western Hemisphere is jeopardized.

Although initial infections in a given grove are presumed to involve beetle dispersion of the pathogen, secondary spread within a planting apparently occurs via root grafts between infected and healthy trees. Effective management of root graft transmission is a primary concern in LW-affected groves. Current recommendations for LW control involve the prompt diagnosis of affected trees, rapid removal and destruction of these trees (sanitation), and the treatment of adjacent trees with fungicide and insecticide.

The loss of native members of the Lauraceae family is of ecological significance [1], but LW could also have a considerable economic impact [3] [4]. Since LW could cause a permanent reduction in the long-term profitability of the Florida avocado industry, growers, policy makers, and other stakeholders are concerned about the disease's future impact on the industry, how limited resources should be allocated to mitigate its threat, and how long-term survival of the industry might be ensured. The damage that LW could cause to the industry has been estimated [3] [5], but profitability scenarios have not been examined for the industry. With the disease affecting commercial production, guidelines are needed to assess net revenues using different LW management scenarios. Moreover, a framework is required to evaluate the cost-effectiveness of different LW management strategies which could affect the spread rates. Preliminary work in the latter area indicates that considerable progress is needed before efficacious measures become economically viable [6].

Within this context, the present research was undertaken to assess the potential economic impact of LW and provide producers with a decision tool with which returns could be maximized in the presence of this disease. The approach of Salifu et al. [7] was used to address how LW impacts profitability by considering different disease spread rates and incidences, the age of plantings when they were first affected by the disease, and treatment costs. In general, simulation techniques were used to determine when a grove affected by LW would cease to be profitable with and without management.

\section{Potential Economic Impact of LW on Commercial Avocado}

Avocado is planted on about 3400 hectares in Florida, and represents $60 \%$ of the total area planted in tropical fruits in the state. Most commercial avocado orchards are in Miami-Dade County in South Florida, and 93\% of the plantings are smaller than 7 hectares [3]. Farm-gate value for Florida avocados is in excess of US \$24 million $\cdot \mathrm{yr}^{-1}$, with a wholesale market value upwards of US $\$ 35$ million. The Florida avocado industry has an overall economic impact of US $\$ 100$ million and generates about 550 full-time jobs [8]. The property on which mature avocado trees are grown in Florida is valued at US \$326 million [3].

Evans and Crane [5] estimated unit replacement costs for commercial avocado trees in South Florida as US \$330, based on the Tree Value Analysis internet tool developed at the University of Florida [9]. Trees were calculated as assets whose value was determined using the income method. The approach used by Evans and Crane [5] accounted for lost income from the sale of fruits (a farm gate price for fruit of $\$ 1.21 \mathrm{~kg}^{-1}$ ), and considered the expense of tree removal $\left(\$ 150\right.$ tree $\left.^{-1}\right)$, land preparation, replacement trees, planting, maintenance during a seven-year replacement period (fertilizer, pruning, weeding, and pest control), and a discount rate of $5 \%$.

To assess the economic impact of LW on Florida avocado, Evans et al. [3] considered direct and indirect losses resulting from a hypothetical outbreak of the disease. Direct losses were due to lost income, lower property values, and increased management costs, which included disease monitoring, plant protection products, dead tree disposal, and replanting costs (Table 1). Indirect losses referred to secondary or spillover effects in associated businesses, such as those that sell trees, fertilizer, fungicide, and packaging materials, as well as packing houses, transportation services, and retailers (Table 2). An input-output model (I-O), known as Impact 
Table 1. Direct monetary impact on Florida commercial avocado production under different LW scenarios.

\begin{tabular}{cccc}
\hline Expense/loss category & \multicolumn{3}{c}{ Relative loss in production } \\
\cline { 2 - 4 } & $100 \%$ & $75 \%$ & $50 \%$ \\
\hline Potential losses in fruit sales $^{*}$ & $\$ 30,000,000$ & $\$ 22,500,000$ & $\$ 15,000,000$ \\
Decline in property value $^{* *}$ & $\$ 326,250,000$ & $\$ 244,688,000$ & $\$ 163,125,000$ \\
Disease management costs & $\$ 0$ & $\$ 4,525,000$ & $\$ 4,525,000$ \\
Total direct loss & $\$ 356,250,000$ & $\$ 271,713,000$ & $\$ 182,650,000$ \\
\hline
\end{tabular}

*Based on the value of a mature avocado tree. ${ }^{* *}$ Monitoring, fungicide, and labor costs, as indicated by Evans et al. [3].

Table 2. Potential indirect impact of LW outbreak on Florida’s economy.

\begin{tabular}{cccc}
\hline Considered impact & $100 \%$ loss & $75 \%$ loss & 50\% loss \\
\hline Industry sales & $30,000,000$ & $22,500,000$ & $4,000,000$ \\
Output impacts & $54,266,259$ & $409,699,694$ & $27,133,129$ \\
Employment impacts & 546 & $14,755,704$ & $9,837,136$ \\
Labor income impacts & $19,674,272$ & $1,396,811$ & 931,207 \\
\hline
\end{tabular}

Source: Excerpted from Evans et al. [3].

Analysis for Planning (IMPLAN), was used to quantify indirect losses [3].

Given the uncertain impact of this disease on avocado production, Evans et al. [3] evaluated three different scenarios: 1) total loss, 2) 75\% loss, and 3) 50\% loss. They obtained a unit value of US $\$ 500$ for mature avocado trees by using the Tree Value Analysis internet tool [9], which is very sensitive to analysis parameters.

The following input parameters were used in the analysis by Evans et al. [3]: the average price received by growers in 2012 (US $\$ 1 \mathrm{~kg}^{-1}$ fruit); cost for tree removal (US \$150); and increases in management costs (included US $\$ 733 \mathrm{ha}^{-1} \cdot \mathrm{yr}^{-1}$ for vector control through labor and insecticide). Considering these parameters and a total (100\%) loss scenario, it was estimated that industry sales would decline US \$30 million, and about US $\$ 54.3$ million would be lost to Florida’s GDP (Table 1). In terms of employment, it was estimated that 546 jobs would be lost, representing worker earnings of US \$19.7 million and tax revenue of US \$1.9 million that would not circulate in Florida's economy. It was also estimated that indirect losses would total about US \$77 million $\cdot \mathrm{yr}^{-1}$ (Table 2).

\section{Model Parameters}

Economic and biological data were utilized to develop the described profitability model. To parameterize the model, a production function was created for avocado in Florida. Yearly avocado production was estimated with linear regressions in which the economic life of an orchard was assumed to be 40 years and production decreased after year 30 at an annual rate of 5\% [10]. The derived model was statistically significant and explained up to $70 \%$ of the variation in avocado production (Appendix Table A1).

Most of the economic data were obtained from the Florida Cooperative Extension Service. They reflected South Florida avocado cultivation costs, which included plant nutrition, pest control, weed control and pruning, and represented $40 \%$ of the total costs for production. Fixed costs were $30 \%$ of the total costs and included land rent, supervision, and overhead. Ancillary activities, which included from harvesting to marketing, accounted for the remaining 30\% (Appendix Table A2). Establishment/replanting costs for a hectare of avocado were calculated to be US $\$ 5742$ (around US\$30 per tree), and the cost to produce a kilogram (kg) of fruit was calculated to be US $\$ 0.77$, which included the cost of picking, packing, and marketing (US $\$ 0.37 \mathrm{k}^{-1}$ ) [10]. Based on the average farm gate price received by Florida producers over the last 10 years (US $\$ 1.1 \mathrm{~kg}^{-1}$ ), a net return of US $\$ 0.33 \mathrm{~kg}^{-1}$ of avocado fruit was obtained (Appendix Table A3) [11].

\section{Model Development}

With one of the goals of the present research being to develop a model with which profitability could be as- 
sessed in the presence of LW, the model assumes that an avocado orchard is an asset with a useful lifetime and a stream of net benefits during that time. The model estimates the economic impact of LW by applying the income method developed by Spreen et al. [12]. Future costs and revenues are estimated to obtain net revenue per annum, and net future revenue is discounted such that the net present value (NPV) is obtained using the formula

$$
\mathrm{NPV}=\sum_{t=1}^{T} \frac{\left(p Q_{t}-c_{t} Q_{t}-F\right)}{(1+r)^{t-1}}
$$

where $t$ indexes the corresponding time period; $p$ is the price paid per kilogram of fruit after packing and marketing; $Q_{t}$ is the marketable yield per hectare of avocado in time period $t ; c_{t}$ represents the variable costs per hectare (harvesting, packing, and marketing) at time period $t ; F$ represents production costs (sanitary, irrigation, weed control, and nutrition expenses) and fixed costs (land, supervision, and overhead) per hectare; and $r$ is the discount rate.

It should be noted that LW affects net revenue by both decreasing fruit production (causing the death of trees in the orchard) and increasing management costs (scouting, sanitation, and any prophylactic treatments). The anticipated increase in management costs can therefore be accommodated in the model through an adjustment (reduction) of the net price received for fruit by producers. In this application, net price is adjusted downward by assuming a $10 \%$ increase in total costs due to LW management. Higher percent adjustments are also considered but cause the operation to become unprofitable due to slim profit margin growers currently realize.

The effect of LW on avocado production is obtained as indicated by Salifu et al. [7]. To calculate the value of disease incidence at time $t$, Salifu et al. [7] considers the effective contact rate of disease spread $(\beta)$, the age of the grove at first detection $\left(a_{0}\right)$, and the incidence of the disease at first detection $\left(D_{0}\right)$. A unique solution of when to destroy all trees in the orchard or to replant can be determined with these variables. The profit maximizing objective implies that producers will stay in the avocado business until operating costs become greater than returns, at which time they will either exit the business or replant the orchard if resistant varieties are available.

For the model with LW, a Gompertz-type disease incidence function is used, which drives the epidemic to $100 \%$ incidence, similar to Salifu et al. [7]. The disease spread model describes disease incidence $D_{t}$ over time as

$$
D_{t}=\mathrm{e}^{\ln \left(D_{0}\right) \mathrm{e}^{-\beta t}}
$$

Equation (2) contains two important parameters. The first is the rate of disease spread $(\beta)$, which is also known as the effective contact rate. $\beta$ values of $0.1 \%, 120 \%, 230 \%$, and $350 \%$, which are considered below, indicate the speed of disease transmission over a period of one year. Preliminary data gathered in South Florida avocado orchards during 2012 indicate that LW incidence increases from 1\% to 90\% within a year if no action is taken against LW. The latter means that if disease incidence starts with one case $\left(D_{0}=1 \%\right)$, a beta value (spread rate) equal to 350\% will be required for depicting the "do nothing" strategy, leading to $90 \%$ incidence after a year of initial infection (Figure 1).

\section{Model Scenarios}

The lifespan of each model scenario is defined as the time between planting and destruction or replacement of the avocado orchard. In this regard, two criteria can be used to assess the economic viability of the orchard. The first criterion centers on estimating the time when the increased management costs associated with the spread of the disease and the reduction in yields due to tree removal (sanitation) results in net returns becoming negative (i.e., costs exceed revenues). The second criterion is based on the calculation of the NPV based on a discount rate of $10 \%$. A positive NPV indicates that an operation is profitable, and a negative NPV indicates that it is not profitable. Using these two criteria, a grower can assess the relative profitability of various management strategies, assuming various rates of spread and incidence of disease when first detected.

Four scenarios are considered based on the management strategy that is adopted and its relative efficacy. The first scenario (Do Nothing) assumes that no action is taken to limit the spread of the disease, hence a spread rate of $350 \%$ per annum. The second scenario (Fully Effective) assumes that action is taken with a fully effective control treatment; under this scenario, the value of the parameter beta from Equation (2) decreases to $0.1 \%$. The remaining scenarios consider intermediate levels of control effectiveness: scenario three (Low Effectiveness) assumes that the control strategy reduces beta to 230\%, and scenario four (Intermediate Effectiveness) reduces 


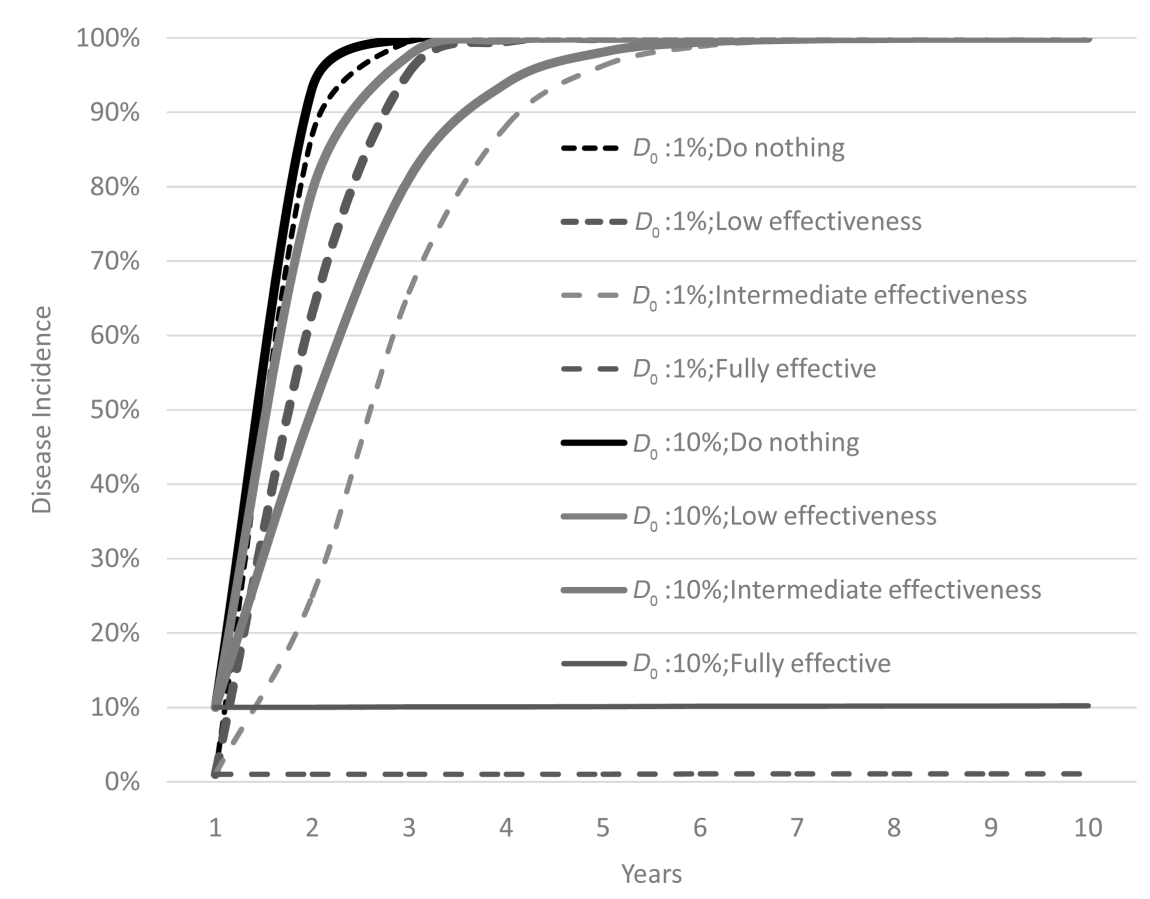

Figure 1. Disease incidence along time according to the considered laurel wilt possible spread rates (Gompertz).

beta to $120 \%$. For each scenario, the two levels of disease incidence at first detection $\left(D_{0}\right)$ considered are $1 \%$ and 10\% (i.e., respectively, 2 and 20 affected trees out of 192 trees, which corresponds to plant density in avocado groves).

The $10 \%$ increase in production costs due to LW management considers the narrow profit margins evident in a previous analysis [8], and translates to a net price, $p$, of US $\$ 0.25 \mathrm{~kg}^{-1}$. Avocado production in the presence of LW is simulated with the previously mentioned spread rates, $\beta$, of $0.1 \%, 120 \%, 230 \%$, 350\%, and initial incidences, $D_{0}$, of $1 \%$ and $10 \%$ after LW is detected on a yearly basis. It is assumed that LW may affect an avocado orchard at any age. Thus, for 1\% initial disease incidences, the optimal period at which net returns becomes negative is determined for each scenario, relating to the effectiveness of control measures and the investment value when total tree removal would be advisable (Table 3 and Table 4, respectively). Similar analyses estimate the $10 \%$ initial disease incidence (Table 5 and Table 6 , respectively).

\section{Results and Discussions}

LW is a disease that threatens Florida avocado orchards. Given its lethal nature and how fast it kills avocado trees, major concerns for the future of the Florida avocado industry have arisen. Unfortunately, many questions about the epidemiology of LW are unresolved, which has prevented scientists from devising a cost-efficient means of controlling the disease.

An empirical economic model is used to determine when all trees in an orchard affected by LW would need to be destroyed due to negative net returns. Large differences in profitability are determined for avocado orchards affected by hypothetical outbreaks of laurel wilt, depending on whether control measures are utilized and the extent to which these measures are effective.

Table 3 shows the optimal period at which a net return becomes negative for a $1 \%$ initial disease incidence under four different scenarios (see also Figure 2). For example, in column 1 of Table 3, if a seven-year-old orchard (row 3) were to become infected with the disease in a situation using no control measures (Do Nothing, scenario 1), LW would spread so rapidly that the orchard would need to be destroyed within two years (by year 9) of detection of the disease in the orchard. Similar results are obtained for both the low effectiveness $(\beta=230 \%)$ and intermediate effectiveness $(\beta=120 \%)$ scenarios (i.e., scenarios 3 and 4 , respectively). In contrast, a fully effective control strategy (scenario 2) that decreases the LW spread rate to $0.1 \% \mathrm{yr}^{-1}$ would $^{2}$ 
Table 3. Period at which a net return becomes negative according to age at initial LW infection, assuming $10 \%$ cost increase, and $D_{0}=1 \%{ }^{*}$.

\begin{tabular}{|c|c|c|c|c|}
\hline $\begin{array}{l}\text { Orchard age in years } \\
\qquad a_{0}\end{array}$ & $\begin{array}{c}\text { Do nothing } \\
\beta=350 \%\end{array}$ & $\begin{array}{c}\text { Fully effective } \\
\beta=0.1 \%\end{array}$ & $\begin{array}{l}\text { Low effectiveness } \\
\qquad \beta=230 \%\end{array}$ & $\begin{array}{l}\text { Intermediate effectiveness } \\
\qquad \beta=120 \%\end{array}$ \\
\hline 5 & 7 & 39 & 7 & 7 \\
\hline 6 & 8 & 39 & 8 & 8 \\
\hline 7 & 9 & 39 & 9 & 9 \\
\hline 8 & 10 & 39 & 10 & 10 \\
\hline 9 & 11 & 39 & 11 & 11 \\
\hline 10 & 12 & 39 & 12 & 12 \\
\hline 11 & 13 & 39 & 13 & 13 \\
\hline 12 & 14 & 39 & 14 & 14 \\
\hline 13 & 15 & 39 & 15 & 15 \\
\hline 14 & 16 & 39 & 16 & 16 \\
\hline 15 & 17 & 39 & 17 & 17 \\
\hline 16 & 18 & 39 & 18 & 18 \\
\hline 17 & 19 & 39 & 19 & 19 \\
\hline 18 & 20 & 39 & 20 & 20 \\
\hline 19 & 21 & 39 & 21 & 21 \\
\hline 20 & 22 & 39 & 22 & 22 \\
\hline 21 & 23 & 39 & 23 & 23 \\
\hline 22 & 24 & 39 & 24 & 24 \\
\hline 23 & 25 & 39 & 25 & 25 \\
\hline 24 & 26 & 39 & 26 & 26 \\
\hline 25 & 27 & 39 & 27 & 27 \\
\hline 26 & 28 & 39 & 28 & 28 \\
\hline 27 & 29 & 39 & 29 & 29 \\
\hline 28 & 30 & 39 & 30 & 30 \\
\hline 29 & 31 & 39 & 31 & 31 \\
\hline 30 & 32 & 39 & 32 & 32 \\
\hline 31 & 33 & 39 & 33 & 33 \\
\hline 32 & 34 & 39 & 34 & 34 \\
\hline 33 & 35 & 39 & 35 & 35 \\
\hline 34 & 36 & 39 & 36 & 36 \\
\hline 35 & 37 & 39 & 37 & 37 \\
\hline 36 & 38 & 39 & 38 & 38 \\
\hline 37 & 39 & 39 & 39 & 39 \\
\hline
\end{tabular}

${ }^{*} \beta=$ the rate of LW spread, $a_{0}=$ the age of the grove at first detection, $D_{0}=$ the incidence of laurel wilt at first detection. Total costs increase due to treatment. 
Table 4. NPV according to age of initial infection and control strategy scenarios, assuming control strategy increases costs $10 \%$, and $D_{0}=1 \%{ }^{*}$.

\begin{tabular}{|c|c|c|c|c|}
\hline $\begin{array}{l}\text { Orchard age in years } \\
\qquad a_{0}\end{array}$ & $\begin{array}{c}\text { Do nothing } \\
\beta=350 \%\end{array}$ & $\begin{array}{c}\text { Fully effective } \\
\beta=0.1 \%\end{array}$ & $\begin{array}{l}\text { Low effectiveness } \\
\qquad \beta=230 \%\end{array}$ & $\begin{array}{l}\text { Intermediate effectiveness } \\
\qquad \beta=120 \%\end{array}$ \\
\hline 5 & -5545 & 12,236 & -8571 & -8490 \\
\hline 6 & -2696 & 12,388 & -6394 & -6311 \\
\hline 7 & -89 & 12,541 & -4399 & -4315 \\
\hline 8 & 2308 & 12,680 & -2568 & -2491 \\
\hline 9 & 4487 & 12,806 & -903 & -833 \\
\hline 10 & 6467 & 12,921 & 611 & 674 \\
\hline 11 & 8268 & 13,025 & 1987 & 2044 \\
\hline 12 & 9905 & 13,120 & 3238 & 3290 \\
\hline 13 & 11,393 & 13,206 & 4375 & 4422 \\
\hline 14 & 12,746 & 13,284 & 5409 & 5452 \\
\hline 15 & 13,976 & 13,355 & 6348 & 6388 \\
\hline 16 & 15,094 & 13,419 & 7203 & 7238 \\
\hline 17 & 16,111 & 13,478 & 7980 & 8012 \\
\hline 18 & 17,035 & 13,531 & 8686 & 8715 \\
\hline 19 & 17,875 & 13,580 & 9327 & 9354 \\
\hline 20 & 18,638 & 13,624 & 9911 & 9935 \\
\hline 21 & 19,333 & 13,664 & 10,442 & 10,464 \\
\hline 22 & 19,964 & 13,700 & 10,924 & 10,944 \\
\hline 23 & 20,538 & 13,733 & 11,362 & 11,380 \\
\hline 24 & 21,059 & 13,763 & 11,761 & 11,777 \\
\hline 25 & 21,533 & 13,790 & 12,123 & 12,138 \\
\hline 26 & 21,964 & 13,814 & 12,452 & 12,466 \\
\hline 27 & 22,356 & 13,837 & 12,752 & 12,764 \\
\hline 28 & 22,713 & 13,857 & 13,024 & 13,035 \\
\hline 29 & 23,036 & 13,875 & 13,272 & 13,282 \\
\hline 30 & 23,299 & 13,892 & 13,467 & 13,476 \\
\hline 31 & 23,512 & 13,906 & 13,619 & 13,627 \\
\hline 32 & 23,681 & 13,919 & 13,734 & 13,741 \\
\hline 33 & 23,814 & 13,930 & 13,819 & 13,825 \\
\hline 34 & 23,916 & 13,939 & 13,879 & 13,884 \\
\hline 35 & 23,994 & 13,947 & 13,919 & 13,923 \\
\hline 36 & 24,051 & 13,953 & 13,942 & 13,946 \\
\hline 37 & 24,091 & 13,959 & 13,952 & 13,956 \\
\hline
\end{tabular}

${ }^{*} \beta=$ the rate of LW spread, $a_{0}=$ the age of the grove at first detection, $D_{0}=$ the incidence of laurel wilt at first detection. Total costs increase due to treatment. NPV is calculated from planting to the period in which net returns become negative. 
Table 5. Period at which net returns become negative according to age at LW initial infection, assuming $10 \%$ cost increase, and $D_{0}=10 \%{ }^{*}$.

\begin{tabular}{|c|c|c|c|c|}
\hline $\begin{array}{l}\text { Orchard age in years } \\
\qquad a_{0}\end{array}$ & $\begin{array}{c}\text { Do nothing } \\
\beta=350 \%\end{array}$ & $\begin{array}{l}\text { Fully effective } \\
\qquad \beta=0.1 \%\end{array}$ & $\begin{array}{l}\text { Low effectiveness } \\
\qquad \beta=230 \%\end{array}$ & $\begin{array}{l}\text { Intermediate effectiveness } \\
\qquad \beta=120 \%\end{array}$ \\
\hline 5 & 7 & 33 & 7 & 7 \\
\hline 6 & 8 & 33 & 8 & 8 \\
\hline 7 & 9 & 33 & 9 & 9 \\
\hline 8 & 10 & 34 & 10 & 10 \\
\hline 9 & 11 & 34 & 11 & 11 \\
\hline 10 & 12 & 34 & 12 & 12 \\
\hline 11 & 13 & 34 & 13 & 13 \\
\hline 12 & 14 & 34 & 14 & 14 \\
\hline 13 & 15 & 34 & 15 & 15 \\
\hline 14 & 16 & 34 & 16 & 16 \\
\hline 15 & 17 & 34 & 17 & 17 \\
\hline 16 & 18 & 34 & 18 & 18 \\
\hline 17 & 19 & 34 & 19 & 19 \\
\hline 18 & 20 & 34 & 20 & 20 \\
\hline 19 & 21 & 34 & 21 & 21 \\
\hline 20 & 22 & 34 & 22 & 22 \\
\hline 21 & 23 & 34 & 23 & 23 \\
\hline 22 & 24 & 34 & 24 & 24 \\
\hline 23 & 25 & 34 & 25 & 25 \\
\hline 24 & 26 & 34 & 26 & 26 \\
\hline 25 & 27 & 34 & 27 & 27 \\
\hline 26 & 28 & 34 & 28 & 28 \\
\hline 27 & 29 & 34 & 29 & 29 \\
\hline 28 & 30 & 34 & 30 & 30 \\
\hline 29 & 31 & 34 & 31 & 31 \\
\hline 30 & 32 & 34 & 32 & 32 \\
\hline 31 & 33 & 34 & 33 & 33 \\
\hline 32 & 34 & 34 & 34 & 34 \\
\hline 33 & 35 & 34 & 34 & 34 \\
\hline 34 & 36 & 35 & 35 & 35 \\
\hline 35 & 37 & 36 & 36 & 36 \\
\hline 36 & 37 & 37 & 37 & 37 \\
\hline 37 & 38 & 38 & 38 & 38 \\
\hline
\end{tabular}

${ }^{*} \beta=$ the rate of LW spread, $a_{0}=$ the age of the grove at first detection, $D_{0}=$ the incidence of laurel wilt at first detection. Total costs increase due to treatment. 
Table 6. NPV according to age of initial infection and control strategy scenarios, assuming control strategy increases costs $10 \%$, and $D_{0}=10 \%{ }^{*}$.

\begin{tabular}{|c|c|c|c|c|}
\hline $\begin{array}{c}\text { Orchard age in years } \\
a_{0}\end{array}$ & $\begin{array}{c}\text { Do nothing } \\
\beta=350 \%\end{array}$ & $\begin{array}{c}\text { Fully effective } \\
\beta=0.1 \%\end{array}$ & $\begin{array}{l}\text { Low effectiveness } \\
\qquad \beta=230 \%\end{array}$ & $\begin{array}{l}\text { Intermediate effectiveness } \\
\qquad \beta=120 \%\end{array}$ \\
\hline 5 & -6848 & -2819 & -9875 & -9794 \\
\hline 6 & -4013 & -1336 & -7711 & -7628 \\
\hline 7 & -1286 & 158 & -5596 & -5512 \\
\hline 8 & 1219 & 1516 & -3656 & -3580 \\
\hline 9 & 3497 & 2751 & -1892 & -1823 \\
\hline 10 & 5568 & 3873 & -289 & -226 \\
\hline 11 & 7450 & 4892 & 1169 & 1226 \\
\hline 12 & 9162 & 5819 & 2494 & 2546 \\
\hline 13 & 10,718 & 6661 & 3699 & 3746 \\
\hline 14 & 12,132 & 7426 & 4794 & 4837 \\
\hline 15 & 13,418 & 8122 & 5790 & 5829 \\
\hline 16 & 14,586 & 8754 & 6695 & 6731 \\
\hline 17 & 15,649 & 9328 & 7518 & 7550 \\
\hline 18 & 16,615 & 9850 & 8266 & 8295 \\
\hline 19 & 17,493 & 10,324 & 8946 & 8973 \\
\hline 20 & 18,292 & 10,755 & 9564 & 9589 \\
\hline 21 & 19,017 & 11,146 & 10,126 & 10,148 \\
\hline 22 & 19,677 & 11,502 & 10,637 & 10,657 \\
\hline 23 & 20,277 & 11,824 & 11,102 & 11,120 \\
\hline 24 & 20,822 & 12,118 & 11,524 & 11,541 \\
\hline 25 & 21,318 & 12,384 & 11,908 & 11,923 \\
\hline 26 & 21,769 & 12,626 & 12,257 & 12,270 \\
\hline 27 & 22,178 & 12,845 & 12,574 & 12,586 \\
\hline 28 & 22,551 & 13,045 & 12,862 & 12,874 \\
\hline 29 & 22,889 & 13,226 & 13,125 & 13,135 \\
\hline 30 & 23,172 & 13,390 & 13,340 & 13,349 \\
\hline 31 & 23,402 & 13,532 & 13,509 & 13,517 \\
\hline 32 & 23,586 & 13,654 & 13,639 & 13,646 \\
\hline 33 & 23,732 & 13,759 & 13,746 & 13,753 \\
\hline 34 & 23,846 & 13,841 & 13,830 & 13,835 \\
\hline 35 & 23,933 & 13,898 & 13,888 & 13,893 \\
\hline 36 & 24,003 & 13,935 & 13,927 & 13,931 \\
\hline 37 & 24,059 & 13,956 & 13,949 & 13,952 \\
\hline
\end{tabular}

${ }^{*} \beta=$ the rate of LW spread, $a_{0}=$ the age of the grove at first detection, $D_{0}=$ the incidence of laurel wilt at first detection. Total costs increase due to treatment. NPV is calculated from planting to the period in which net returns become negative. 
enable the orchard to remain profitable over the economic life of the crop. Under this scenario, when $D_{0}=1 \%$, net returns would become negative in year 39 (Table 3, Figure 2).

Table 4 presents the value of the orchard at the time when total replanting would be recommended. Thus using the earlier example in which a seven-year-old orchard becomes infected with the disease, the orchard would need to be destroyed immediately using the strategies in scenarios 1,3 , and 4 (the relative values of the investments can be obtained from Table 4). In particular, the values of the investment would be -US $\$ 89$ (do nothing, scenario 1), -US \$4399 (low effectiveness, scenario 3), and -US \$4315 (intermediate effectiveness, scenario 4), respectively. The larger negative values associated with the latter two strategies are due to the additional management costs assumed. However, in the situation where the management strategy was fully effective to lower the spread rate below $0.1 \%$ (scenario 2), the relative value of the investment at the time of the suggested replantation would be approximately US $\$ 12,541$. In general, the information provided in Table 4 suggests that, orchards younger than eight-year-old would not be economically viable (negative NPV values) after an LW attack, if the control strategy is not fully effective; these orchards would need to be destroyed immediately and would only be replanted if aresistant variety were available or if a fully effective control measure were employed thereafter. The information presented in Table 5 and Table 6, see also Figure 3, where $D_{0}=10 \%$, can be interpreted in a similar fashion to that present in Table 3 and Table 4.

In general, the model suggests that minimal impacts by marginally effective control measures (low effectiveness and intermediate effectiveness) result from a less than fully effective strategy. When one considers the NPV for these marginally effective scenarios, the model yields that groves younger than ten-year-old should be destroyed immediately after a LW attack if $D_{0}=1 \%$ (Table 4), or if $D_{0}=10 \%$ (Table 6, Figure 2) due to negative NPV values. The latter highlights the importance of treating LW opportunely.

In summary, a control strategy that lowers the spread rate to either $230 \%$ (scenario 3) or $120 \%$ (scenario 4 ) would have no effect on the time period in which negative net revenue is obtained and immediate destruction of the orchard is indicated, compared to the "Do Nothing" strategy (scenario 1). Encouraging results were found only if a completely effective control strategy (scenario 2) were available. Consequently, a control strategy that is fully effective in controlling the spread of LW at a maximum $10 \%$ of the current production costs is required to keep avocado growers in Florida in business. LW incidence when first detected impacts the optimal period of destruction of all orchard trees due to negative net returns and is negatively related to NPV. In addition, there is a negative relationship between costs and the time of tree destruction since increased costs due to control measures become greater than the returns. The only exception to this outcome is when the spread rate is reduced to $0.1 \%$. It should be noted that this model will still be useful as the understanding of the disease, pathogen, vector, and host improves.

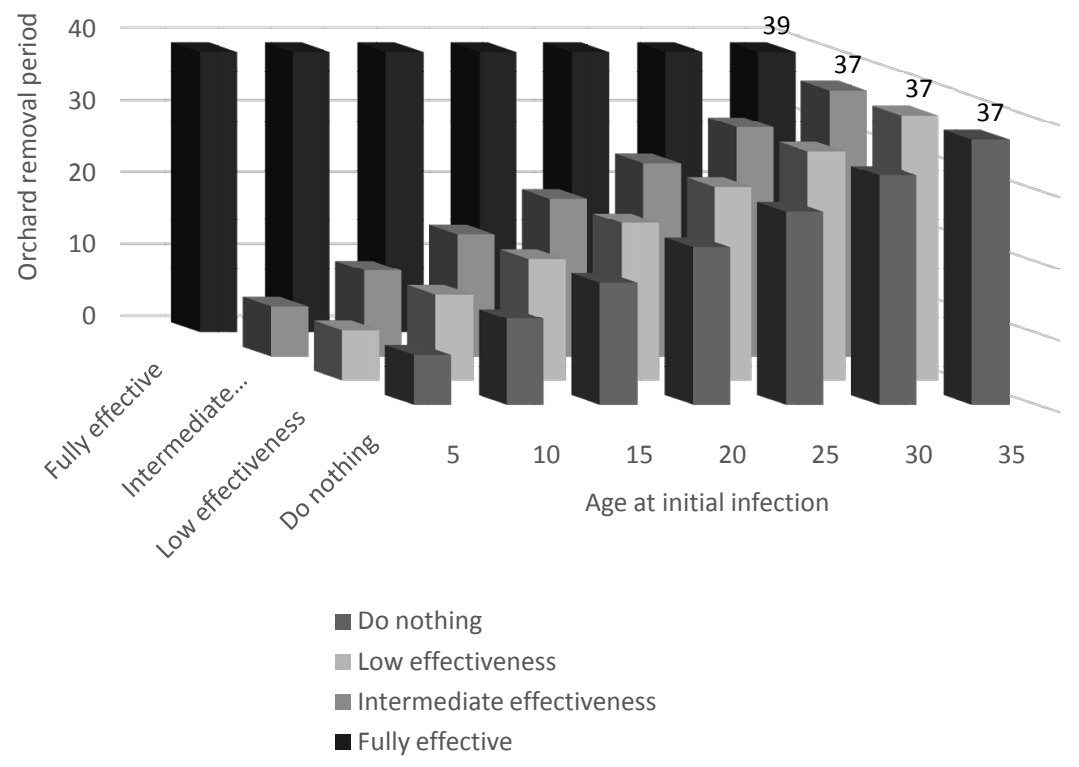

Figure 2. Period at which net returns become negative according to age at LW initial infection, assuming $10 \%$ cost increase, and $D_{0}=1 \%$. 

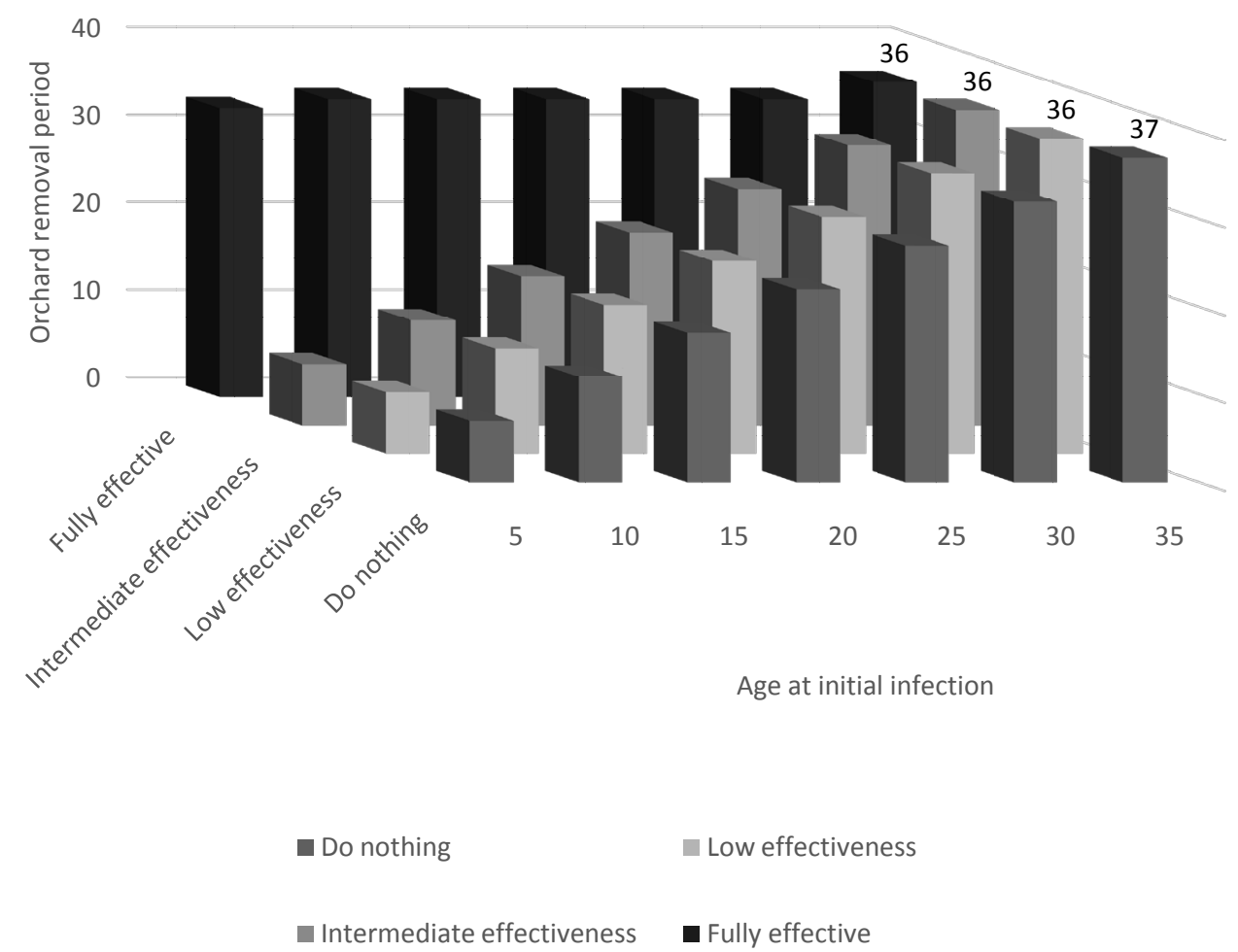

Figure 3. Period at which net returns become negative according to age at LW initial infection, assuming $10 \%$ cost increase, and $D_{0}=10 \%$.

This paper contributes to the literature by providing a decision framework for completely destroying/replanting an orchard in the presence of disease. The framework integrates an epidemiological model and an economic model into a bio-economic model that allows for ex-ante evaluation of various management strategies. The results of our investigation indicate that due to the aggressive nature of the LW disease, nothing less than an effective management strategy that slows the spread of the disease to less than $0.1 \%$ per annum would be effective. Early detection (permanent scouting) and elimination of diseased tissues and vectors are therefore of paramount importance. However, given the slim profit margin, such a strategy cannot exceed more than about $10 \%$ of the cost of production, under the current assumptions. The insights given in this paper are widely applicable to other diseases affecting perennial tree crops. The approach for cost quantification is generic and thus suitable for application to other diseases affecting perennial crops. A major limitation of the model is that it requires that the behavior of the disease and the effectiveness of the proposed control measures be reasonably well known. In cases where this information is not well known, the model could be strengthened by using stochastic distributions for key parameters such as spread rate.

\section{References}

[1] Fraedrich, S.W., Harrington, T.C., Rabaglia, R.J., Ulyshen, M.D., Mayfield III, A.E., Hanula, J., Eickwort, J.M. and Miller, D.R. (2008) A Fungal Symbiont of the Redbay Ambrosia Beetle Causes a Lethal Wilt in Redbay and Other Lauraceae in the Southeastern United States. Plant Disease, 92, 215-224. http://dx.doi.org/10.1094/PDIS-92-2-0215

[2] Kendra, P.E., Niogret, J., Montgomery, W.S., Sanchez, J.S., Deyrup, M.A., Pruett, G.E., Ploetz, R.C., Epsky, N.D. and Heath, R.R. (2012) Temporal Analysis of Sesquiterpene Emissions from Manuka and Phoebe Oil Lures and Efficacy for Attraction of Xyleborus Glabratus (Coleoptera: Curculionidae: Scolytinae). Journal Economic Entomology, 105, 659669. http://dx.doi.org/10.1603/EC11398

[3] Evans, E.A., Crane, J., Hodges, A. and Osborne, J.L. (2010) Potential Economic Impact of Laurel Wilt Disease on the Florida Avocado Industry. Hortechnology, 20, 235-238.

[4] Evans, E. and Nalampang, S. (2010) Sample Avocado Production Costs and Profitability Analysis for Florida. UF/ IFAS Extension, Gainesville. 
[5] Evans, E.A. and Crane, J. (2009) Estimates of the Replacement Costs of Commercial and Backyard Avocado Trees in South Florida. UF/IFAS Extension, Gainesville.

[6] Ploetz, R.C., Pérez-Martinez, J.M., Evans, E.A. and Inch, S.A. (2011) Toward Fungicidal Management of Laurel Wilt of Avocado. Plant Disease, 95, 977-982. http://dx.doi.org/10.1094/PDIS-08-10-0595

[7] Salifu, A.W., Grogan, K.A., Spreen, T.H. and Roka, F.M. (2012) Economic Analyses of Strategies to Combat HLB in Florida Citrus. SAEA Conference, Birmingham.

[8] Evans, E. and Lozano, I.B. (2014) Sample Avocado Production Costs and Profitability Analysis for Florida. UF/IFAS Extension, Gainesville.

[9] UF/TREC (University of Florida, Tropical Research and Education Center) (2006) Interactive Tools-Tree Value Analysis. http://agecon.centers.ufl.edu/TreeCostAvocado.htm

[10] UF/TREC (University of Florida, Tropical Research and Education Center) (2012) Interactive Tools-Tree Value Analysis. http://agecon.centers.ufl.edu/TreeCostAvocado.htm

[11] USDA/NASS (United States Department of Agriculture, National Agricultural Statistics Service) (2013) Avocado Price Received, Measured in Tons. http://quickstats.nass.usda.gov/results/

[12] Spreen, T.H., Zansler, M.L. and Muraro, R.P. (2003) The Costs and Value Loss Associated with Florida Citrus Groves Exposed to Citrus Canker. Proceedings of the Florida State Horticultural Society, 116, 289-294. http://fshs.org/proceedings-o/2003-vol-116/289-294.pdf 


\section{Appendix: Model Used to Parameterize the Model on Laurel Wilt (No Disease Scenario)}

\section{Potential Yield (kg/ha/Month)}

Estimated model: $Y_{t}=\left(\alpha_{1}+\alpha_{2} * a_{t}+\alpha_{3} * a_{t}^{2}\right)$, where $Y_{t}$ represents the expected yield and $a_{t}$ is the orchard age expressed in terms of years.

Table A1. OLS estimates of the effect of age and age squared on yield.

\begin{tabular}{cc}
\hline Parameter & Estimator \\
Intercept $\left(\alpha_{1}\right)$ & $1636.3419^{* * *}$ \\
& $(570.1165)$ \\
$\alpha_{2}$ & $616.1789^{* * *}$ \\
& $(64.1302)$ \\
$\alpha_{3}$ & $-13.8150^{* * *}$ \\
$\mathrm{~N}$ & $(1.5168)$ \\
F test (p value) & 40 \\
R squared & 46.53 \\
\hline
\end{tabular}

${ }^{*}=\mathrm{p}<0.10,{ }^{* *}=\mathrm{p}<0.05$, and $^{* * *}=\mathrm{p}<0.001$, where $\mathrm{p}$ is the $\mathrm{p}$-value. Standard error is in parentheses.

Table A2. Costs per hectare of producing avocado in South Florida.

\begin{tabular}{|c|c|c|c|c|c|c|c|c|c|}
\hline & Year 1 & Year 2 & Year 3 & Year 4 & Year 5 & Year 6 & Year 7-Year 30 & Year 35 & Year 40 \\
\hline \multicolumn{10}{|l|}{ Cultivation Costs } \\
\hline Fertilizer & 431 & 538 & 646 & 754 & 861 & 1400 & 1723 & 1723 & 1723 \\
\hline Fungicide & 108 & 108 & 323 & 323 & 323 & 543 & 646 & 646 & 646 \\
\hline Herbicide & 431 & 431 & 431 & 370 & 370 & 370 & 370 & 370 & 370 \\
\hline Insecticide & 26 & 54 & 108 & 162 & 215 & 269 & 323 & 323 & 323 \\
\hline Pruning & 108 & 108 & 151 & 431 & 431 & 431 & 732 & 732 & 732 \\
\hline Irrigation & 86 & 86 & 86 & 86 & 123 & 123 & 123 & 123 & 123 \\
\hline Moving & 1271 & 1271 & 775 & 711 & 495 & 495 & 495 & 495 & 495 \\
\hline $\begin{array}{l}\text { Total cultivation cost } \\
\text { per hectare (I) }\end{array}$ & 2459 & 2595 & 2520 & 2836 & 2819 & 3631 & 4412 & 4412 & 4412 \\
\hline \multicolumn{10}{|l|}{ Fixed Costs } \\
\hline Landrent & 1238 & 1238 & 1238 & 1238 & 1238 & 1238 & 1238 & 1238 & 1238 \\
\hline Supervision & 384 & 384 & 384 & 384 & 384 & 384 & 384 & 384 & 384 \\
\hline Overhead & 743 & 743 & 743 & 743 & 743 & 743 & 743 & 743 & 743 \\
\hline Total fixed cost per hectare (II) & 2364 & 2364 & 2364 & 2364 & 2364 & 2364 & 2364 & 2364 & 2364 \\
\hline Preharvestcosts (I) + (II) & 4823 & 4959 & 4883 & 5200 & 5183 & 5995 & 6776 & 6776 & 6776 \\
\hline \multicolumn{10}{|l|}{$\begin{array}{l}\text { Harvest and Marketing } \\
\text { Costs Per Hectar }\end{array}$} \\
\hline Sales charge (III) & 0 & 0 & 281 & 748 & 1496 & 1683 & 1870 & 1447 & 1120 \\
\hline Pick, haul, and pack (IV) & 0 & 0 & 673 & 1795 & 3590 & 4039 & 4488 & 3473 & 2687 \\
\hline $\begin{array}{c}\text { Total } \\
\text { Costs }(\mathrm{I})+(\mathrm{II})+(\mathrm{III})+(\mathrm{IV})\end{array}$ & 4823 & 4959 & 5837 & 7743 & 10,269 & 11,717 & 13,134 & 11,696 & 10,583 \\
\hline
\end{tabular}

Source: http://agecon.centers.ufl.edu. 
Table A3. Parameters used for the model.

Planting density per hectare (number of trees)

192

Discount rate (percentage)

$10 \%$

Sales charge (per kilogram)

0.11

Pick, haul and pack (per kilogram)*

Production costs (per kilogram)

Price received by grower at farm gate (per kilogram)

US $\$ 1.1$

Stump removal cost (per tree)

150

Cost of a new tree

20
Cost to plant a new tree

10

"Included in the production costs. Source: http://agecon.centers.ufl.edu. 